\title{
Effective Punching Shear and Moment Capacity of Flat Plate- Column Connection with Shear Reinforcements for Lateral Loading
}

\author{
Jin-Kyu Song, ${ }^{1), *}$ Jubum Kim, ${ }^{2)}$ Ho-Bum Song, ${ }^{3)}$ and Jeong-Won Song ${ }^{4)}$
}

(Received September 16, 2011, Revised February 20, 2012, Accepted February 22, 2012)

\begin{abstract}
In this study, three isolated interior flat slab-column connections that include three types of shear reinforcement details; stirrup, shear stud and shear band were tested under reversed cyclic lateral loading to observe the capacity of slab-column connections. These reinforced joints are $2 / 3$ scale miniatures designed to have identical punching capacities. These experiments showed that the flexural failure mode appears in most specimens while the maximum unbalanced moment and energy absorbing capacity increases effectively, with the exception of an unreinforced standard specimen. Finally, the results of the experiments, as wel 1 as those of experiments previously carried out by researchers, are applied to the eccentricity shear stress model presented in ACI 318 08. The failure mode is therefore defined in this study by considering the upper limits for punching shear and unbalanced momen $t$. In addition, an intensity factor is proposed for effective widths of slabs that carry an unbalanced moment delivered by bending.
\end{abstract}

Keywords: flat plate structures, punching shear, unbalanced moment, M-V plane, shear band.

\section{Introduction}

Because reinforced concrete flat plate structures do not contain beams, they are able to transfer all the loads acting on slabs directly to the columns. At the time when the loads are transferred, all moments that are generated by the delivery load and critical sections that resist the moment (See Figure 1) also converge on the slabs near the columns. When a moment is caused by a delivery load, it is an unbalanced moment that occurs because of a direct shear moment originating from a vertical load and eccentricity and to the lateral load of a vertical load. In ACI 318-08, ${ }^{1}$ it is assumed that part of an unbalanced moment $\left(\gamma_{f} M_{u n b}\right)$ is transferred by bending and that the remainder is transferred $\left(\gamma_{v} M_{u n b}\right)$ by shear. According to the eccentric shear transfer model, the shear force on connections rises if the acting unbalanced moment increases. On the other hand, it is assumed that the unbalanced moment strength does not affect the punching shearing strength in terms of resistance capacity, since the punching shearing strength that resists shear force and the unbalanced moment strength that resists the unbalanced moment are designed independently in the design cri-

\footnotetext{
${ }^{1)}$ Department of Architectural Engineering, Chonnam National University, Gwangju 500-757, Korea

*Corresponding Author; E-mail: jgsong@ jnu.ac.kr

${ }^{2)}$ Department of Civil Engineering, Penn State Harrisburg, Harrisburg, PA 17507, USA

${ }^{3)}$ Research Institute of Structural Engineering \& System, DongYang Structural Engineers Co., Ltd., Seoul, Korea.

${ }^{4}$ Department of Architectural Engineering, Chonnam National University, Gwangju 500-757, Korea.

Copyright (c) 2012, Korea Concrete Institute. All rights reserved, including the making of copies without the written permission of the copyright proprietors.
}

teria. However, the punching shear and unbalanced moment are interrelated in terms of the acting load as well as the resistance strength of the member that resists them. For example, if the resistance strength to the unbalanced moment increases concurrently with an increase in the bending reinforcement ratio of the slabs near the column, then the resistance to punching shear reduces because the risk of damage, such as the occurrence of cracks, decreases. In addition, if the shear reinforcing materials are installed, not only the punching shear resistance capacity, but also the unbalanced moment resistance and energy absorbing capacity in the connections increases.

In ACI 318-08, ${ }^{1}$ the punching shear strength $\left(V_{n P}^{S R}\right)$ of shear reinforcement slabs is presented as follows in Eq. 1:

$$
V_{n P}^{S R}=V_{c}+V_{s} \leq 1 / 2\left(\sqrt{f_{c k}} b_{0} d\right)
$$

In Eq. $1, V_{c}$ is the punching shear strength for concrete slabs (1/ $\left.6\left(\sqrt{f_{c k}} b_{0} d\right)\right)$ and $V_{s}$ is the punching shear strength for reinforcing materials. In the design criteria, the maximum value of Eq. 1 is

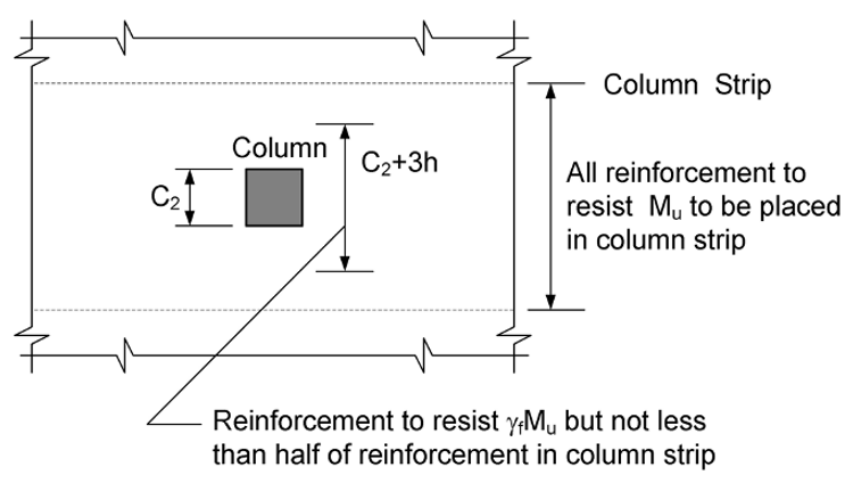

Fig. 1 Location of critical and effective section in flat plates. 
Table 1 Properties of test specimen.

\begin{tabular}{|c|c|c|c|c|c|c|c|c|c|}
\hline (1) & (2) & (3) & (4) & (5) & (6) & $(7)^{* 1}$ & $(8)^{* 2}$ & (9) & $(10)^{* 3}$ \\
\hline Source & Label & $\begin{array}{c}\text { Shear } \\
\text { Reinforcement }\end{array}$ & $\begin{array}{c}f_{c k} \\
(\mathrm{MPa})\end{array}$ & $\frac{V_{g}}{V_{c}}$ & \begin{tabular}{|c|}
$M_{\text {test }}^{S R}\left(M_{\text {test }}\right)$ \\
$(\mathrm{kN} . \mathrm{m})$
\end{tabular} & $\begin{array}{c}V_{\text {test }}^{S R}\left(V_{\text {test }}\right) \\
(\mathrm{kN}) \\
\end{array}$ & $\begin{array}{c}V_{n}^{S R}\left(V_{n}\right) \\
(\mathrm{kN})\end{array}$ & $\frac{V_{\text {test }}^{S R}}{V_{\text {test }}}\left(\frac{V_{\text {test }}}{V_{\text {test }}}\right)$ & $\begin{array}{c}\text { Final failure } \\
\text { mode }\end{array}$ \\
\hline \multirow{4}{*}{$\begin{array}{l}\text { Islam \& Park } \\
(1976)^{5}\end{array}$} & $3 \mathrm{C}$ & None & 29.7 & 0.23 & $(35.8)$ & (177) & $(160)$ & $(1.00)$ & $\mathrm{P}$ \\
\hline & $6 \mathrm{CS}$ & Stirrups & 28.2 & 0.24 & 38.4 & 188 & 234 & 1.06 & $F$ \\
\hline & $7 \mathrm{CS}$ & Stirrups & 29.7 & 0.24 & 41.7 & 202 & 240 & 1.14 & $F$ \\
\hline & $8 \mathrm{CS}$ & Stirrups & 22.1 & 0.27 & 34.9 & 174 & 207 & 0.98 & $\mathrm{~F}$ \\
\hline \multirow{4}{*}{$\begin{array}{l}\text { Robertson } \\
\text { et al. }(2002)^{9}\end{array}$} & $1 \mathrm{C}$ & None & 35.4 & 0.21 & (58.3) & (254) & $(260)$ & $(1.00)$ & $\mathrm{F} / \mathrm{P}$ \\
\hline & $2 \mathrm{CS}$ & Stirrups & 31.4 & 0.22 & 68.5 & 288 & 367 & 1.13 & $\mathrm{~F}$ \\
\hline & $3 \mathrm{SL}$ & Stirrups & 43.4 & 0.17 & 71.0 & 291 & 432 & 1.15 & $\mathrm{~F}$ \\
\hline & $4 \mathrm{HS}$ & Studs & 38.2 & 0.20 & 67.9 & 286 & 405 & 1.13 & $\mathrm{~F}$ \\
\hline \multirow{5}{*}{$\begin{array}{c}\text { Elgabry \& } \\
\text { Ghali }(1987)^{3}\end{array}$} & 1 & None & 35.0 & 0.45 & (130) & $(566)$ & (335) & $(1.00)$ & $\mathrm{P}$ \\
\hline & 2 & Studs & 33.7 & 0.46 & 162 & 668 & 493 & 1.18 & $\mathrm{~F}$ \\
\hline & 3 & Studs & 39.0 & 0.85 & 142 & 754 & 530 & 1.33 & $\mathrm{~F} / \mathrm{P}$ \\
\hline & 4 & Studs & 40.8 & 0.83 & 150 & 780 & 542 & 1.38 & $\mathrm{~F} / \mathrm{P}$ \\
\hline & 5 & Studs & 45.6 & 1.18 & 105 & 786 & 573 & 1.39 & $\mathrm{~F} / \mathrm{P}$ \\
\hline \multirow{10}{*}{$\begin{array}{l}\text { Hawkins et al. } \\
\qquad(1989)^{4}\end{array}$} & $9.6 \mathrm{AH}$ & None & 30.7 & 0.51 & (97.9) & (459) & (369) & $(1.00)$ & $\mathrm{P}$ \\
\hline & 9.6ЕН.34 & Stirrups & 25.5 & 0.59 & 99.8 & 477 & 505 & 1.04 & $F$ \\
\hline & 9.6ЕН.48 & Stirrups & 25.8 & 0.67 & 86.2 & 466 & 507 & 1.02 & $\mathrm{~F}$ \\
\hline & $9.6 \mathrm{AL}$ & None & 28.9 & 0.72 & (34.6) & (353) & (358) & $(1.00)$ & $\mathrm{F} / \mathrm{P}$ \\
\hline & 9.6EL.34 & Stirrups & 23.4 & 0.90 & 33.3 & 383 & 483 & 1.08 & $\mathrm{~F}$ \\
\hline & 9.6EL.56 & Stirrups & 28.5 & 0.97 & 43.1 & 465 & 533 & 1.32 & $\mathrm{~F}$ \\
\hline & $14 \mathrm{AH}$ & None & 30.3 & 0.58 & $(100.2)$ & $(486)$ & (354) & $(1.00)$ & $\mathrm{P}$ \\
\hline & 14EH.49 & Stirrups & 25.1 & 0.70 & 117.9 & 557 & 483 & 1.15 & $\mathrm{~F}$ \\
\hline & $14 \mathrm{AL}$ & None & 27.0 & 0.95 & $(43.4)$ & $(441)$ & (334) & $(1.00)$ & $\mathrm{P}$ \\
\hline & 14EL.49 & Stirrups & 26.9 & 1.06 & 44.4 & 479 & 500 & 1.08 & $\mathrm{~F}$ \\
\hline \multirow{4}{*}{$\begin{array}{l}\text { Kang \& } \\
\text { Wallace } \\
(2008)^{7}\end{array}$} & $\mathrm{C} 0$ & None & 38.6 & 0.30 & (103) & $(438)$ & $(414)$ & $(1.00)$ & $\mathrm{P}$ \\
\hline & PS2.5 & Thin plate stirrups & 35.1 & 0.32 & 109 & 456 & 592 & 1.04 & $\mathrm{~F}$ \\
\hline & PS3.5 & Thin plate stirrups & 35.1 & 0.32 & 106 & 447 & 592 & 1.02 & $\mathrm{~F}$ \\
\hline & HS2.5 & Studs & 35.1 & 0.32 & 104 & 441 & 592 & 1.01 & $\mathrm{~F}$ \\
\hline \multirow{4}{*}{$\begin{array}{l}\text { This study } \\
\text { (2009) }\end{array}$} & $\mathrm{RC} 1$ & None & 38.7 & 0.43 & $(81.1)$ & $(390)$ & $(361)$ & $(1.00)$ & $\mathrm{P}$ \\
\hline & SR1 & Stirrups & 38.7 & 0.43 & 101.4 & 449 & 542 & 1.15 & $\mathrm{~F}$ \\
\hline & SR2 & Studs & 38.7 & 0.43 & 81.4 & 391 & 542 & 1.00 & $F$ \\
\hline & SR3 & Bands & 38.7 & 0.43 & 99.2 & 443 & 542 & 1.14 & $\mathrm{~F}$ \\
\hline
\end{tabular}

$* 1: V_{\text {test }}=V_{g}+\frac{\gamma_{v} A_{c} c}{J_{c}} M_{\text {test }}, V_{\text {test }}^{S R}=V_{g}+\frac{\gamma_{v} A_{c} c}{J_{c}} M_{t e s t}^{S R}, * 2: V_{n}=\frac{1}{3} \sqrt{f_{c k}} b_{0} d, V_{n}^{S R}=\frac{1}{2} \sqrt{f_{c k}} b_{0} d, * 3: \mathrm{F}$ - flexural failure, $\mathrm{P}$ - punching failure.

limited to 1.5 times the punching shear strength of unreinforced slabs. However, the ACI-ASCE Committee $421^{6}$ allows the design strength to increase when the reinforcing shear $V_{c}$ is $1 / 4$ $\left(\sqrt{f_{c k}} b_{0} d\right)$ by applying a stud and the maximum value can be increased up to $2 / 3\left(\sqrt{f_{c k}} b_{0} d\right)$ in Eq. 6 .

On the other hand, in the design criteria, there are two types of actions (beam action and two-way action), by dividing the slabs into two types, long and narrow width, according to the aspect ratio of slab $\beta$. In the case of the beam action, the maximum shearing strength that concrete can resist is designed by lowering it to $1 / 2$ of the punching shear strength against the two-way action. This is necessary because it is difficult to expect an impact to occur when two-way shear resistance is affected by the transverse restraint of compression struts in connections between slabs and the column. This classification of slab actions according to the aspect ratio works mainly when gravity loads are dominant. In terms of flat plates acting as an element of transverse resistance, if the impact of the unbalanced moment by a transverse load is enhanced, oneway bending behavior also appears in two way slabs. As a consequence, the punching shear capacity of connections may not be fully operated.

In Table 1, the results are examined of experiments carried out on the transverse load of two-way slabs that have interior connections. In Row 19 of Table 1 on the shear strength ratio at the final 
failure, the maximum shearing force is significantly less than the maximum punching shear strength required in most design criteria, with the exception of the case where the gravity load ratio on punching shear strength is high (See Row (5) in Table 1) and where there is no shear reinforcement. This result suggests that flexural failure might occur due to an unbalanced moment before the connections reach maximum shear strength, even if the correct shear reinforcements are installed.

\section{Research significance}

In this study, shear governed failure and bending governed failure are defined by using an $\mathrm{M}-\mathrm{V}$ plane of the unbalanced moment and the punching shear to explain the slab-column connection actions on the shear and unbalanced moment. Furthermore, measures are investigated to reflect the unbalanced moment strength in determining the final punching shear strength on slabs. In addition, the impact of shear reinforcements on punching shear strength and unbalanced moment strength is examined and effective shear strength and effective width enlargement factors are proposed in order to reflect the strength improvement impact by shear reinforcements.

\section{Unbalanced moment and punching shear}

\subsection{Basic concept}

Figure 2 shows the M-V plane, in which the moment and resistance strength are examined based on the eccentricity shear stress model of the design criteria. In the graph, the dotted lines parallel to the vertical and horizontal axes represent the punching shear and unbalanced moment, respectively, and the solid lines indicate the moment due to the acting loads of the slabs. The thick solid lines show the moment of slabs due to the acting load, while the dots $(\bullet)$ in the graph refer to the current state of the applied load, and the thin solid lines represent the expected route of the moment of slabs according to the increase in loads.

In ACI 318-08, ${ }^{1}$ the maximum shear stress on critical sections of slabs is defined by assuming it to be a collated stress of eccentric shear originating from the direct shear and unbalanced moment caused by vertical loads as follows:

$$
v_{\text {max }}=\frac{V_{g}}{A_{c}}+\frac{\gamma_{v} M_{u n b} c}{J_{c}}
$$

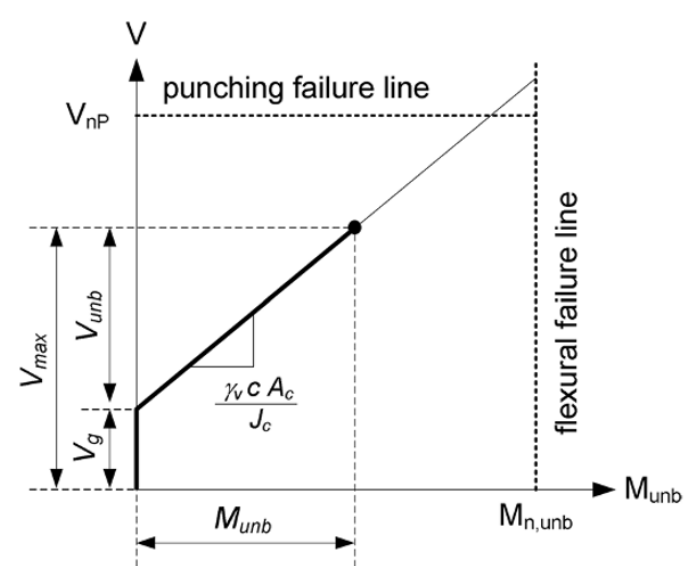

Fig. $2 \mathrm{M}-\mathrm{V}$ plane for the flat plates without shear Reinforcements.
In Eq. 2, $v_{\max }$ is the maximum punching shear stress, $V_{g}$ is the direct shear force due to vertical loads, $A_{c}$ is the critical section areas of slabs, $\gamma_{v}$ is the ratio of unbalanced moment that is delivered by eccentric shear, $M_{u n b}$ is the unbalanced moment, $c$ is the distance from the centroid to the critical sections, and $J_{c}$ is the polar moment of inertia.

When multiplying both sides of Eq. 2 by the critical section area, $A_{c}$, the maximum punching shear force in the critical sections, $V_{\max }$, is as follows in Eq. 3.

$$
V_{\text {max }}=V_{g}+\frac{\gamma_{v} c A_{c}}{J_{c}} M_{u n b}
$$

In this equation, $\gamma_{v} c A_{\mathcal{c}} / J_{c}$ is an invariable number that is set according to the geometrical characteristics of joints between slabs and columns. Let the invariable to $\mathrm{K}$, the maximum punching shear force on critical sections, $V_{\max }$, be the linear equation with a slope $\mathrm{K}$ and y-intercept $V_{g}$, similarly to Eq. 4 . This may be expressed in the graph in Figure 2 as thick solid lines for the unbalanced moment and shear.

$$
V_{\text {max }}=K M_{u n b}+V_{g}, K=\frac{\gamma_{v} c A_{c}}{J_{c}}
$$

In the design criteria, the punching shear strength of a non-reinforcement slab $V_{n P}$, is defined as Eq. 5 below and the values are the same as the punching failure line (dotted horizontal bold line) in Figure 2.

$$
V_{n P}=V_{c}=\frac{1}{3} \sqrt{f_{c k}} b_{0} d
$$

In Eq. $5, V_{c}$ is the punching shear strength of concrete slabs, $f_{c k}$ is the concrete design criteria strength, $b_{0}$ is the circumference of critical sections at the distance of $d / 2$ from the column sides, and $d$ is the effective thickness of slabs.

In addition, under the assumption that part of the unbalanced moment $\gamma_{f} M_{u n b}$, is delivered to the columns by bending, if ACI $318-08^{1}$ is applied, in which the slab areas that deliver bending as $c_{2}+3 h$ is defined, the unbalanced moment strength $M_{n, u n b}$, is as follows in Eq. 6 and the values may be expressed as the flexural failure lines, indicated as the thick and vertical dotted lines shown in Figure 2.

$$
M_{n, u n b}=\frac{M_{n,\left(c_{2}+3 h\right)}}{\gamma_{f}}
$$

In Eq. $6, M_{n,\left(c_{2}+3 h\right)}$ is the flexural strength of slab sections that have a width of $c_{2}+3 h, \gamma_{f}$ is the ratio of the unbalanced moment that is delivered by bending, $c_{2}$ is the width of the columns, and $h$ is the thickness of the slabs in the equation.

\subsection{M-V plane with shear reinforcements}

In the design criteria, the slab sections are defined with a width of $c_{2}+3 h$ for resistance against an unbalanced moment that is delivered by bending, regardless of the installation of shear reinforcements. However, according to existing research results, ${ }^{6-10}$ the shear reinforced slabs have a smooth plastic redistribution of flexural reinforcements because shear failure is delayed, unlike unreinforced slabs where flexural moments converge near the columns. This means that the unbalanced moment strength increases because of the expansion of the effective width that resists an 


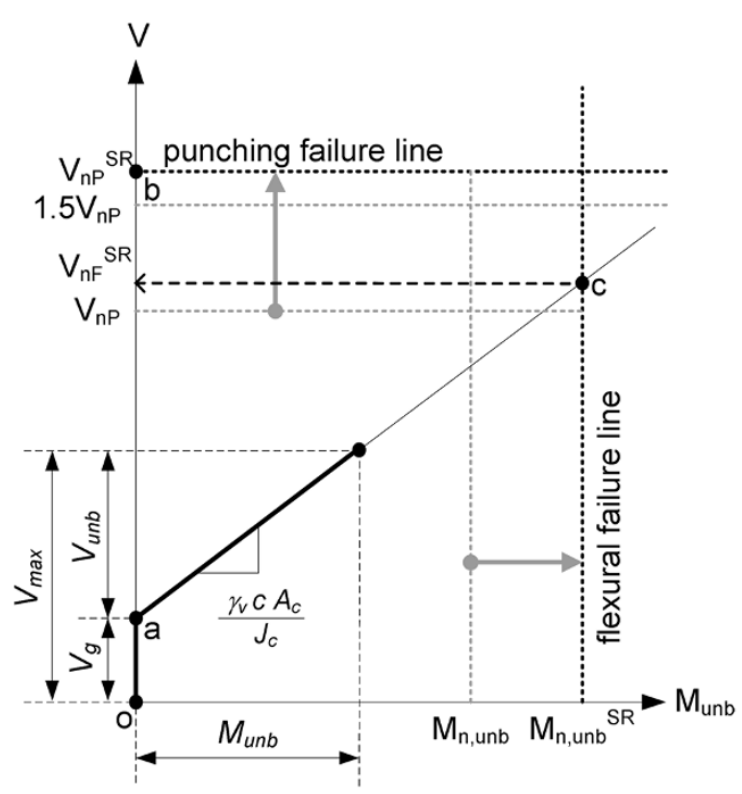

Fig. $3 \mathrm{M}-\mathrm{V}$ plane for the flat plates with shear reinforcements.

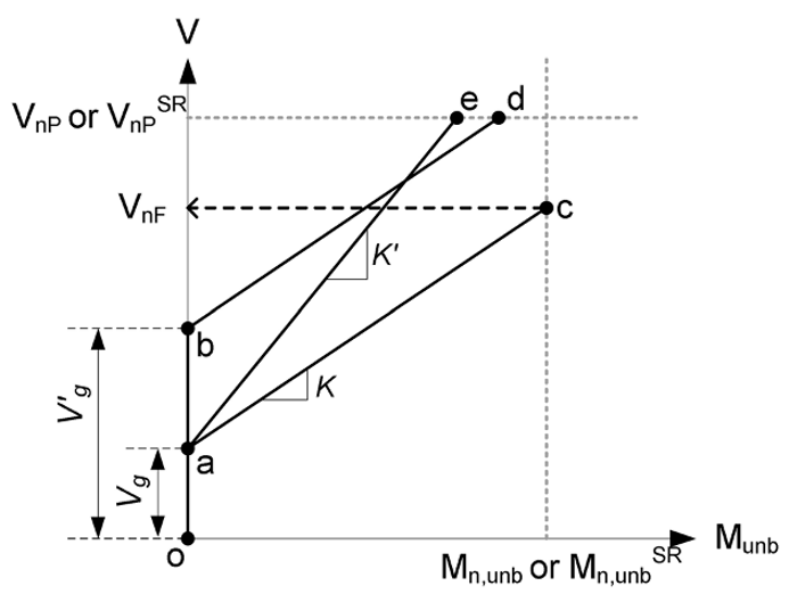

Fig. 4 Various conditions that affect failure modes for the flat plates.

unbalanced moment when flat plate slabs are shear-reinforced. Figure 3 demonstrates the concept of unbalanced moment strength $\left(M_{n, u n b} \rightarrow V_{n, \text { unb }}^{S R}\right)$ caused by an increase in shear strength $\left(V_{n p} \rightarrow\right.$ $\left.V_{n P}^{S R}\right)$ and effective width as shear reinforcements are installed, as has been previously mentioned.

The M-V plane, as shown in Figures 2 and 3, is significantly useful in examining slab actions because it can explain the effect of loads acting on slabs and the resistance capacity of the moment as well as the status of loads received by the current slabs, the remaining load strength additionally received by the current slabs, and the effect of shear reinforcements in the slabs. For example, Figure 3 indicates slabs, on which act the unbalanced moment of $M_{u n b}$ and the maximum punching shear force of $V_{\max }$. In this graph, the maximum punching shear force $V_{\max }$ consists of a direct shear element $V_{g}$ according to vertical loads and an eccentric shear element $V_{u n b}$, due to the unbalanced moment. In Figure 2, the punching shear and unbalanced moment strength of unreinforced slabs are $V_{n P}$ and $M_{n, u n b}$, respectively, while the punching shear and unbalanced moment strength of shear reinforcement slabs are
$V_{n P}^{S R}$ and $M_{n, u n b}^{S R}$, respectively, as shown in Figure 3. When the load increases continually, it is easy to estimate the final failure mode, which is the bending governed failure and the shear governed failure, by using the $\mathrm{M}-\mathrm{V}$ plane. In this plane, the bending governed failure is defined as the case where the unbalanced moment strength reaches maximum strength before shear strength reaches its maximum strength; while shear governed failure is defined as the converse case. Figure 4 is shown to explain the slab failure mode on the $\mathrm{M}-\mathrm{V}$ plane. When vertical loads on joints are small $\left(V_{g}\right)$, bending governed failure occurs on the slabs at point $c$ along the force line $\overline{o a c}$, and when vertical loads are relatively large $\left(V_{g}^{\prime}\right)$, sudden shear governed failure will occur on the slabs at $d$, on the force line $\overline{o b d}$. Meanwhile, when the geometry of joints differs, yet the vertical loads are identical, bending governed failure such as in the force line $\overline{o a c}$ may change into shear governed failure such as in the force line $\overline{o a e}$. Consequently, the failure mode in the slab-column joints is predicted when structures have unexpected extreme loads and when shear reinforcement is carried out in joints, due to the use of reinforced materials.

\section{Experimental investigation}

\subsection{Test program}

A total of four, flat plate interior joints were subjected to gravity and cyclic lateral loads. All specimens had the same configurations except shear reinforcement details at the slab-column connections: control specimen with no shear reinforcement (which is denoted as RC1); stirrups (SR1); headed shear stud (SR2); and shear bands (SR3). The specimens represented a multi-story residential building designed in accordance to ACI 318-08. ${ }^{1}$ Dead and live loads are assumed to be $6.5 \mathrm{kN} / \mathrm{m}^{2}$ and $3.0 \mathrm{kN} / \mathrm{m}^{2}$, respectively. The slabs ( $135 \mathrm{~mm}$ thick) were approximately two-thirds scale with a bay size of $3 \mathrm{~m} \times 3 \mathrm{~m}$ supported by a square column of $300 \mathrm{~mm} \times 300 \mathrm{~mm}$ as shown in Figure 5. The compressive strength of concrete and the yield strength of reinforcement are assumed to be $35 \mathrm{MPa}$ and $400 \mathrm{MPa}$, respectively.

Table 2 shows actual material properties of the specimens. As shown in Figure 6, the spacing of D13 top reinforcement was 100 $\mathrm{mm}$ in the column strip, providing $1.11 \%$ reinforcement ratio, while the spacing was approximately $200 \mathrm{~mm}$ in middle strip ( $0.52 \%$ reinforcement ratio). Bottom reinforcement was spaced at approximately $150 \mathrm{~mm}$ throughout and two bars passed through the column to satisfy the structural integrity requirement of ACI code. The minimum cover was $15 \mathrm{~mm}$. The column consisted of 8-D29 longitudinal reinforcement and D13 stirrups at $100 \mathrm{~mm}$ spacing.

All specimens with shear reinforcement (SR series) were designed to have nominally the same punching shear capacity and $50 \%$ greater than that of the control specimen $\mathrm{RC} 1$.

The reinforcing interval and the width of stirrups are in accordance with the design criteria of ACI 318-08. ${ }^{1}$ With the exception of stirrups, there are no design criteria for other reinforcing materials. Therefore, the study results obtained by $K$. Pilakoutas and $X$. $\mathrm{li}^{8}$ and the ACI Committee $421^{6}$ were referred to for the shear band design and stud design, respectively.

The details of shear reinforcement are explained in Figure 7. SR1 is fabricated from a closed stirrup by using Ø6 circle reinforcements, while seven stirrups were placed on each side of the 


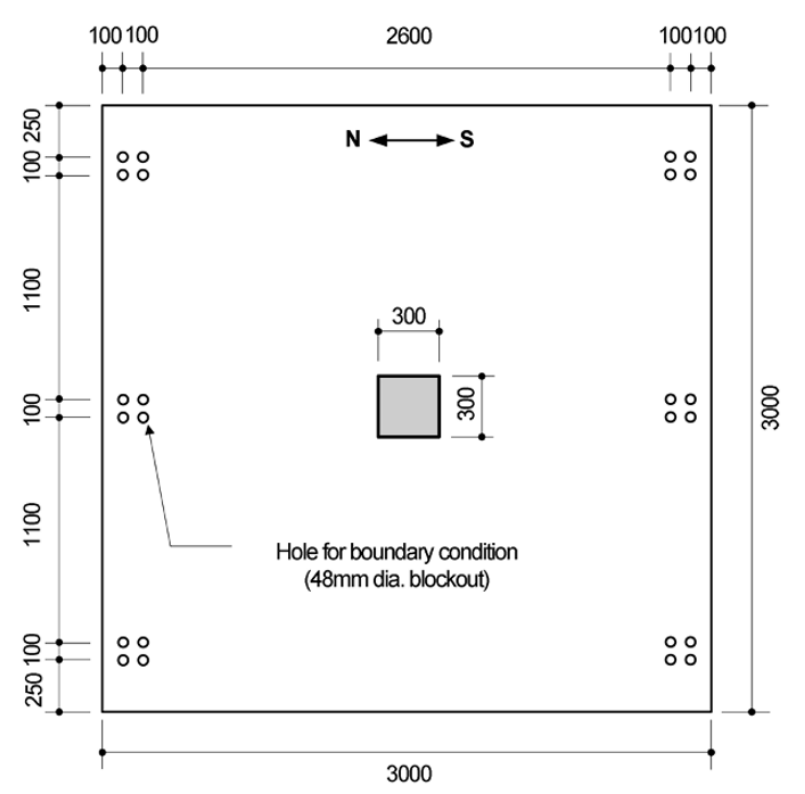

(a) Plan

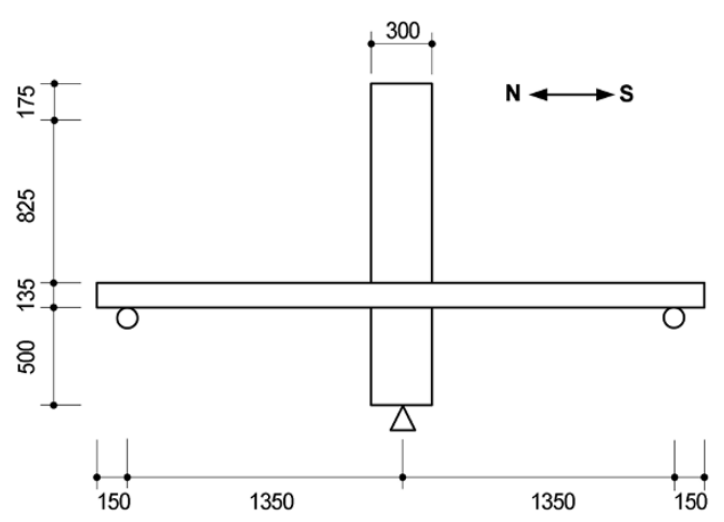

(b) Section

Fig. 5 Test specimens (unit: $\mathrm{mm}$ ).

columns at $45 \mathrm{~mm}$ intervals. SR2 is fabricated from stud rails by welding seven Ø10-stud bolts onto a steel rail at $52 \mathrm{~mm}$ intervals, placed in two rows on each side of the columns. For SR3, holes were drilled regularly on $30 \mathrm{~mm}$ wide and $3 \mathrm{~mm}$ thick band style steel and bend reinforcement materials at $50 \mathrm{~mm}$ intervals between vertical areas were placed on each side of the columns in three rows.

Specimens are installed as shown in Figures 8 and 9. The lower

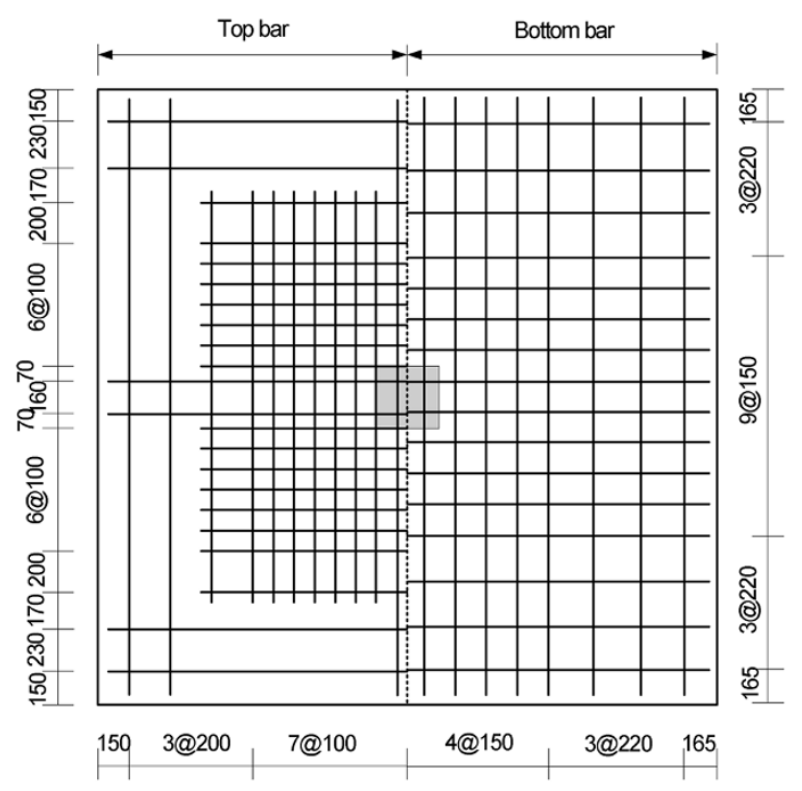

Fig. 6 Placements of top and bottom bars.

parts of the columns in the specimens are fabricated to be hinged and a $3000 \mathrm{kN}$ vertical load cell is installed between the hinge and oil pressure jack for vertical loads. By connecting the hinges that support the columns with right and left base plates by a restraining arm, the horizontal movement in the lower part of the hinge in the columns is restrained. For an actuator, $500 \mathrm{kN}$ was connected to the upper part of the columns and repeated vertical loads of the north and south directions were added. At the ends of the slabs, three vertical links on the south and north directions were installed and by connecting pins to both ends of the vertical links, the horizontal movements and turns have freedom of movement. At the ends of the slabs on the west and east directions, guide rails were installed in order to prevent twisting of the specimens during the experimental process of vertical loads. To measure the responses of the strength and displacement capacity of specimens, two load cells and six displacement cells were installed. In the upper and lower parts of each specimen, twenty strain gauges were attached, with ten strain gauges in shear reinforcement. The strain gauges measure the deformation of flexural reinforcement and shear reinforcing materials. Experiments are carried out according to the gravity loading stage and vertical loading stage. For the gravity load, displacement loads are added by using an oil pressure jack that is installed at the lower part of the columns. A vertical load is

Table 2 Published tests of interior slab-column connection subjected to $\mathrm{V}$ and $\mathrm{M}$.

\begin{tabular}{|c|c|c|c|c|c|c|c|c|c|c|}
\hline \multirow{2}{*}{ Specimen } & \multirow{2}{*}{ 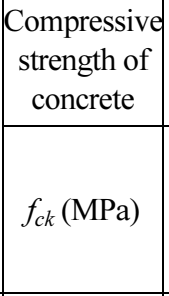 } & \multicolumn{2}{|c|}{ Yield strength of steel } & \multirow{2}{*}{$\begin{array}{l}\text { Column } \\
\text { size } \\
C_{1}, C_{2} \\
(\mathrm{~mm})\end{array}$} & \multirow{2}{*}{$\begin{array}{l}\text { Slab length } \\
l_{1}, l_{2}(\mathrm{~mm})\end{array}$} & \multirow{2}{*}{$\begin{array}{c}\text { Slab } \\
\text { thickness } \\
t(\mathrm{~mm})\end{array}$} & \multirow{2}{*}{$\begin{array}{c}\text { Effective } \\
\text { depth of } \\
\text { slab } d(\mathrm{~mm})\end{array}$} & \multicolumn{2}{|c|}{ Steel ratio } & \multirow{2}{*}{$\begin{array}{c}\text { Type of } \\
\text { shear reinforce- } \\
\text { ment }\end{array}$} \\
\hline & & $\begin{array}{c}\text { Flexural } \\
\text { reinforce- } \\
\text { ments } \\
f_{y}(\mathrm{MPa}) \\
\end{array}$ & $\begin{array}{l}\text { Shear rein- } \\
\text { forcements } \\
f_{v y}(\mathrm{MPa})\end{array}$ & & & & & $\begin{array}{l}\text { Top bar } \\
\rho_{\text {top }}(\%)\end{array}$ & $\begin{array}{c}\text { Bottom bar } \\
\rho_{\text {bottom }}(\%)\end{array}$ & \\
\hline $\mathrm{RC} 1$ & 38.7 & 449 & - & 300 & 3,000 & 135 & 113.5 & 1.06 & 0.79 & Unreinforced \\
\hline SR1 & 38.7 & 449 & 631 & 300 & 3,000 & 135 & 113.5 & 1.06 & 0.79 & Stirrup \\
\hline $\mathrm{SR} 2$ & 38.7 & 449 & 500 & 300 & 3,000 & 135 & 113.5 & 1.06 & 0.79 & Shear stud \\
\hline SR3 & 38.7 & 449 & 346 & 300 & 3,000 & 135 & 113.5 & 1.06 & 0.79 & Shear band \\
\hline
\end{tabular}



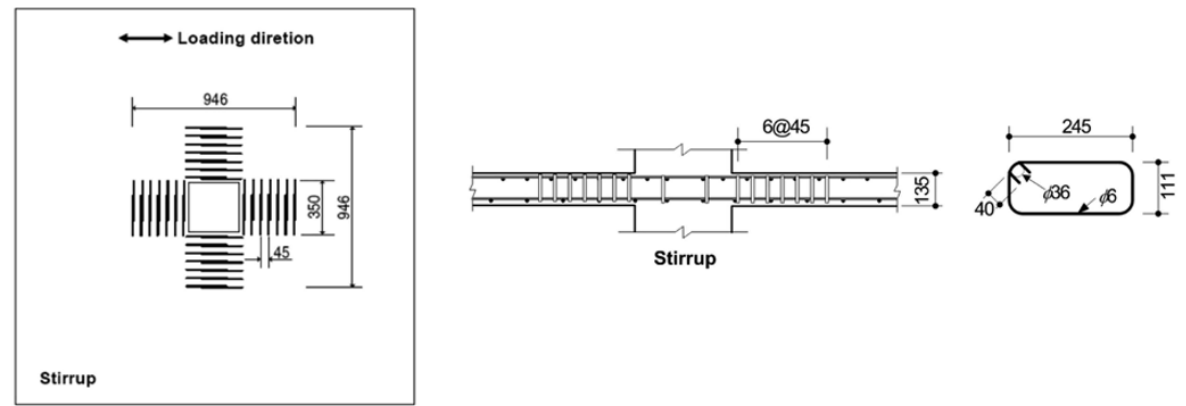

(a) SR1 (Stirrup)
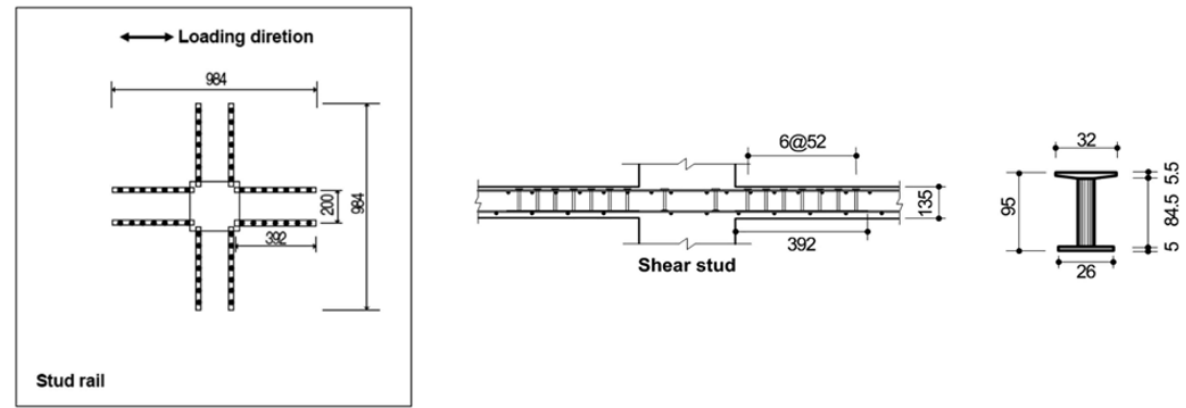

(b) SR2 (Shear stud)
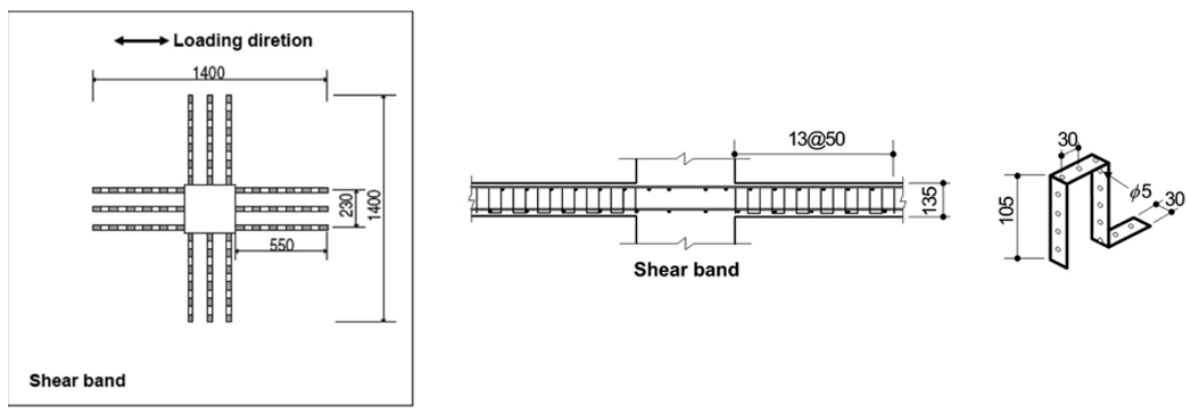

(c) SR3 (Shear band)

Fig. 7 Placements and details of the shear reinforcements (unit: $\mathrm{mm}$ ).

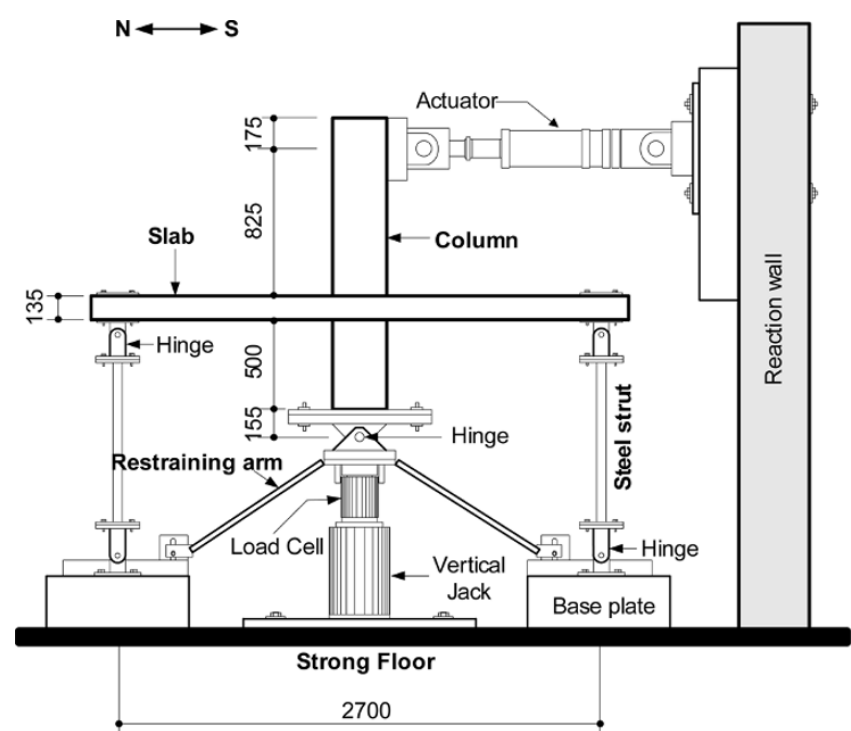

Fig. 8 Installation of test specimen.

monotonously added until it reaches $40 \%$ of the nominal punching strength $\left(=1 / 3\left(\sqrt{f_{c k}} b_{0} d\right)\right)$ of slabs. After the vertical load

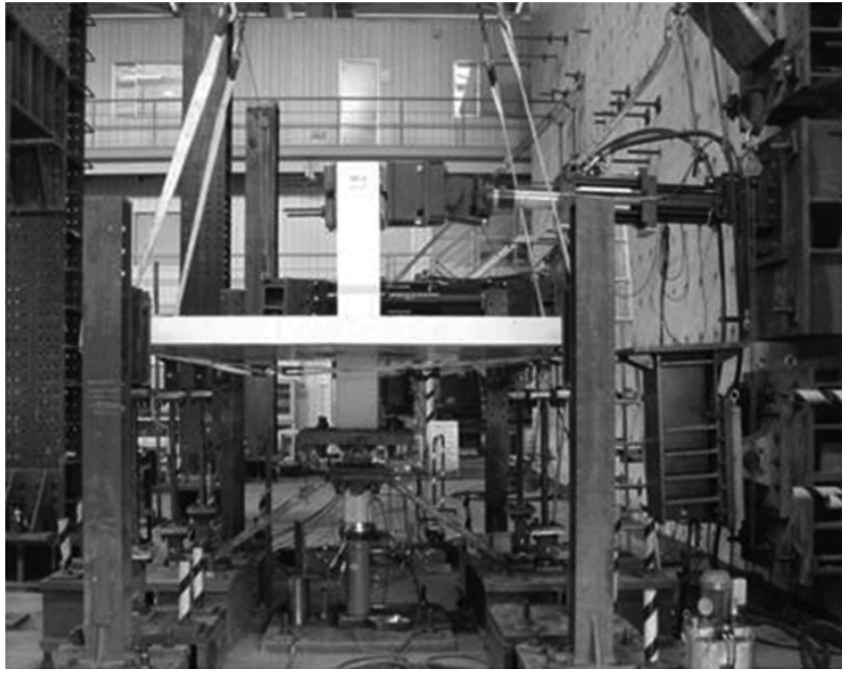

Fig. 9 Photo of set up after installation.

reaches the targeted value, all the measurement instruments are initialized. The history of repeated lateral loads is repeatedly added using the displacement control method according to the displace- 


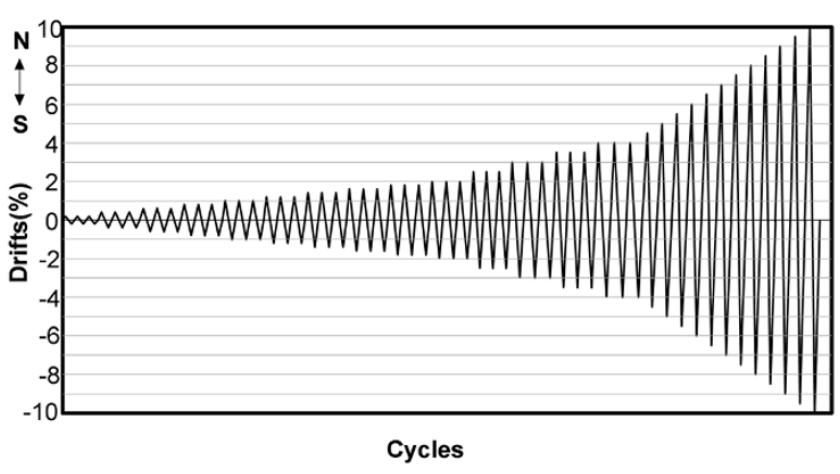

Fig. 10 Loading protocol with displacement control.

ment ratio between stories of a load acting point by using an actuator connected to the upper part of the columns (see Figure 10). While repeated lateral load experiments are operating, we maintain the gravity load ratio on the joints at a certain level by controlling the camber load.

\subsection{Test results}

Figure 11 illustrates the lateral loads and lateral displacement ratio of each specimen. The general behavior of each specimen's response is the same up to a $1 \%$ lateral displacement ratio and the rigidity of specimens decreases gradually with an increase in the lateral displacement ratio. The unreinforced specimen, $\mathrm{RC} 1$, reaches the greatest strength of $50 \mathrm{kN}$ at a $1.4 \%$ lateral displacement ratio and sudden punching destruction occurs at a $1.8 \%$ lateral displacement ratio, with a joint strength of $38 \mathrm{kN}$. After punching, the lateral load strength in the joints reduces to about $20 \%$ of the maximum strength. The strength reduces and is maintained at the strength greater than $40 \mathrm{kN}$ of the $4.1 \%$ lateral dis- placement ratio. Unlike RC1, the SR2 and SR3 specimens, in which the stud and shear band are used, do not show brittle punching after maximum strength is reached. The maximum lateral load strength appears to be $50 \mathrm{kN}$ at a 2.3 lateral displacement ratio and $61 \mathrm{kN}$ at a $2.7 \%$ lateral displacement ratio. SR2 and SR3 maintain the strength of over $40 \mathrm{kN}$ for $4.5 \%$ of the lateral displacement ratio and $8 \%$ of the lateral displacement ratio, respectively. These 3-types of shear reinforcements which have designed to have identical punching shear capacities showed different influences for deformation capacity. Shear band, for example, showed large impact for increasing deformation capacity. It will be estimated that shear reinforcements affect directly for increasing deformation capacity.

A nonlinear pushover analysis is conducted in this study by using FEM for RC1 and SR3 in order to compare and examine the tensile strain rates and stress distribution according to the plastic redistribution of the main reinforcement (See Figure 17). For the analysis program, we used $A T E N A^{2}$ and assumed that the structural equation of concrete was stiffened orthotropic. As for Material modeling, compressive stress-strain relationship of concrete complies with the CEB-FIP model before reaching maximum compressive stress and linear decrease equation was applied characteristics of softening after maximum compressive stress. Elasticity theory complied with tensile stress-strain relationship before cracking. The smeared crack model also was applied for crack. Model proposed by Hordijk complied with biaxial stress failure mode and model proposed by Rankine et al. complied with failure criteria of concrete. In addition, it is assumed that the reinforcement is fully attached to the concrete and that it only has axial stiffness in uniaxial strain as a two-joint point truss element included within the concrete. The comparison between load and displacement on slabs (Figures 11 (a) and (d)) proves that the anal-

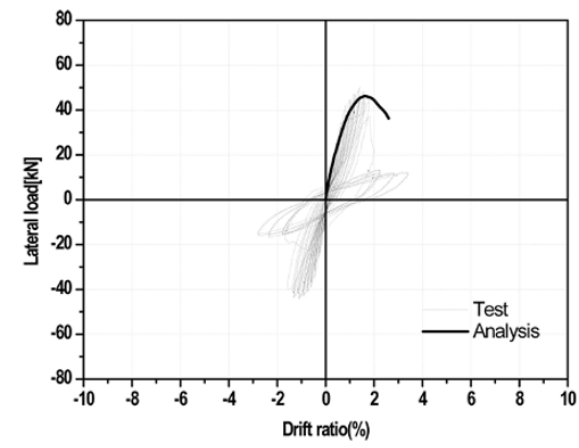

(a) $\mathrm{RC1}$ (without shear reinforcements)

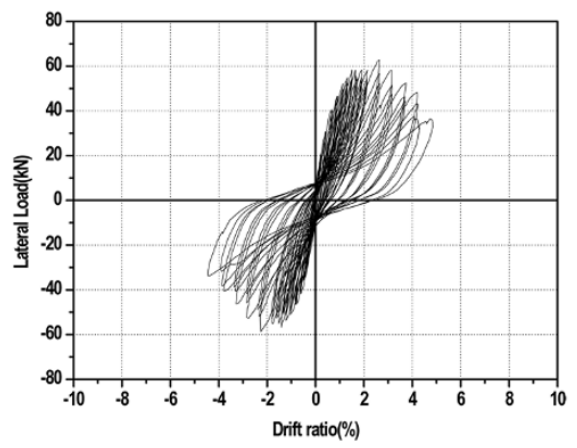

(b) SR1(stirrup)

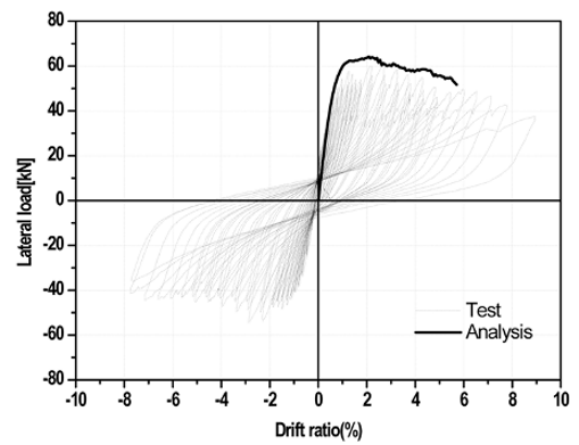

(d) SR3(shear band)

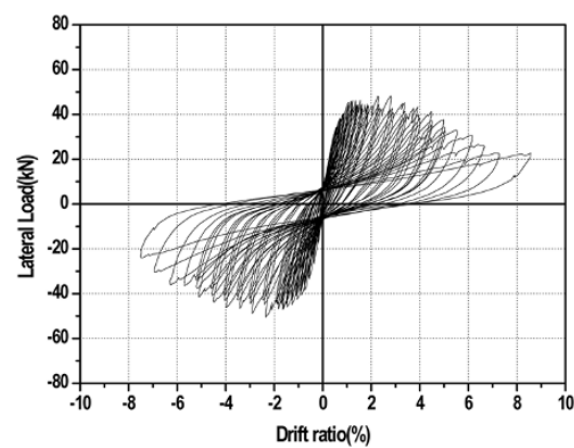

(c) SR2(stud)

Fig. 11 Relations for lateral drift ratio-lateral load. 


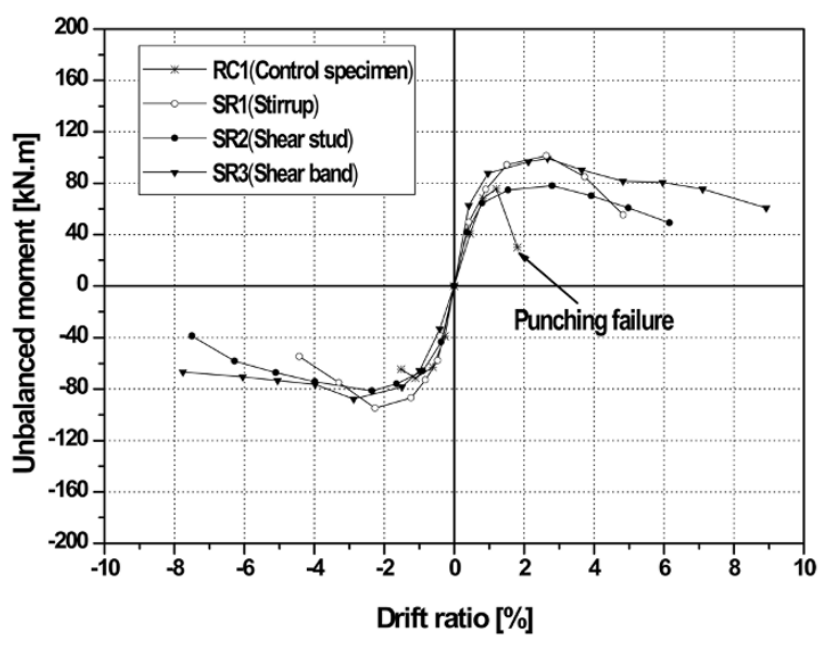

Fig. 12 Envelope curve of the specimens.

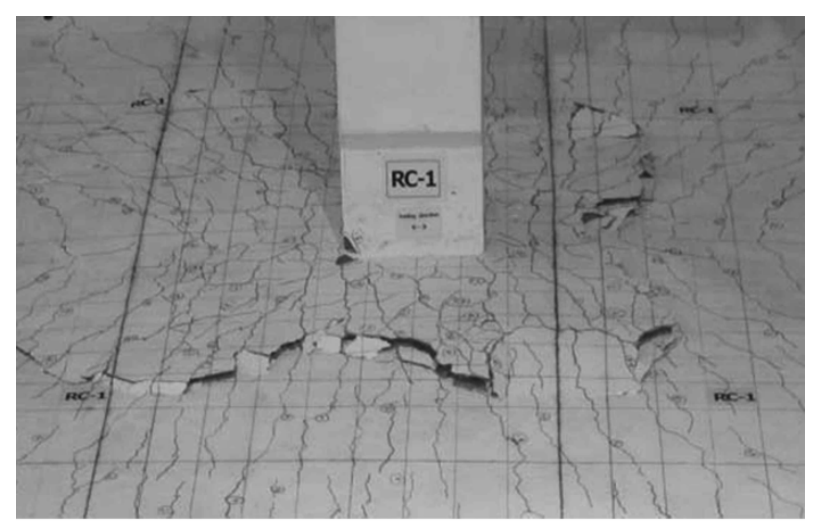

(a) No shear reinforcement

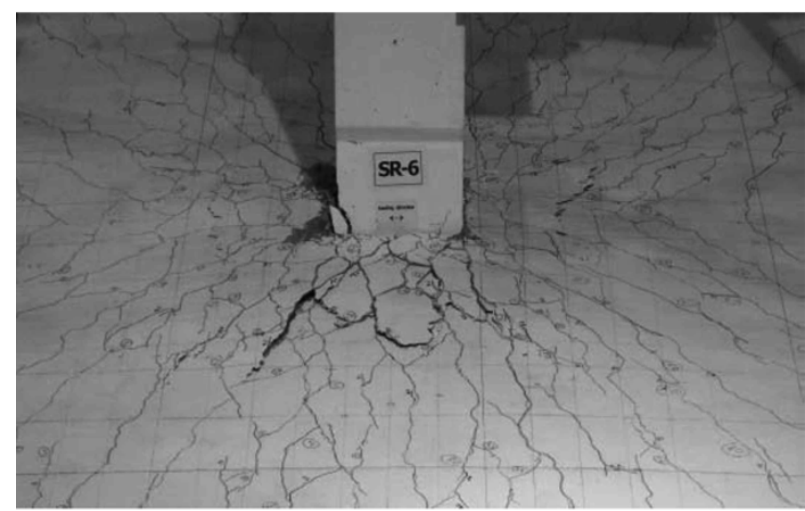

(b) Shear band reinforcement

Fig. 13 Crack pattern of the specimens.

ysis results correctly predict the results of experiments.

Figure 12 shows a comparison of the hysteresis loop of each specimen. The strength and displacement capacity of specimens using shear reinforcement increases significantly compared to that of the unreinforced specimen. SR3, where shear band was used, showed high lateral displacement compared to other reinforced joints.

Figure 13 shows the crack patterns after the addition of the final force on the unreinforced specimen. An examination is carried out each time the repeated lateral displacement ratio cycle ends after the addition of gravity load. Cracks in each specimen occur due to

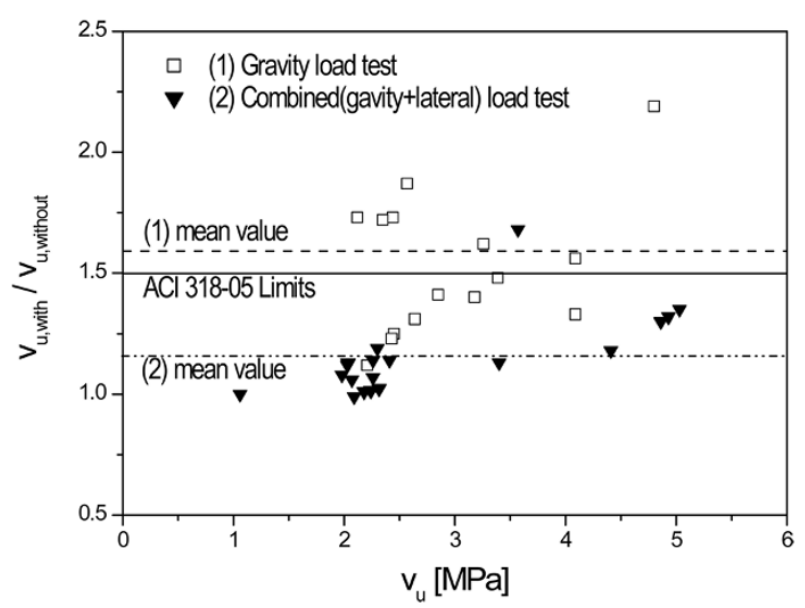

Fig. 14 Punching shear strength ratio of flat plates with and without shear reinforcements.

the process of gravity load addition and the crack patterns are distinctly similar up to about a $1.8 \%$ lateral displacement ratio load. Brittle punching failure appears at a $1.8 \%$ lateral displacement ratio in the $\mathrm{RC} 1$ specimen and punching shear is formed at a distance of about $300 \mathrm{~mm} \sim 550 \mathrm{~mm}$ (about $2.5 \mathrm{~d} \sim 5.0 \mathrm{~d}$ ) from the columns in the upper part of the slabs. The crack spread in reinforced specimens appears continually even after a 1.8\% lateral displacement ratio, while at the final stage, crack damage in the reinforced specimens is considerable, compared to the unreinforced specimen, $\mathrm{RC} 1$.

\section{Strength estimation according to failure mode}

\subsection{Effective punching shear strength in flex- ural failure mode}

Figure 14 shows the results of experiments of a vertical load or combined vertical and lateral loading on existing flat plates. The results of vertical loading are taken from an analysis of the experiments carried out by Keefe(1954), Franz(1963), Marti et al.(1977), Muller et al.(1977), Muller et al.(1984), Chana \& Desai(1991), Yamada et al.(1992), and Beutel \& Hegger(1998), recorded in the International Federation for Structural Concrete (fib) Report ${ }^{10}$ and the results of lateral load are taken from the analysis of experiments obtained by Islam \& Park(1976), ${ }^{5}$ Robertson et al.(2002), Elgabry \& Ghali(1987), ${ }^{3}$ Hawkins et al.(1989), and Kang \& Wallace(2008), ${ }^{7}$ for this study (see Table 1).

In Figure 14, the horizontal axis shows the maximum punching shear stress calculated by using Eq. 2 and the vertical axis shows the punching shear strength rate of shear reinforcement specimens compared to the unreinforced specimen. As can be seen in the graph, when only direct shear occurs due to vertical load ( $\square$ ), the average shear strength rate of shear reinforcement against the unreinforced specimen is 1.63. On the other hand, when eccentric shear due to a lateral load is combined with direct shear ( $\boldsymbol{\nabla})$, the average shear strength ratio is 1.15 , which is a significantly lower value than when only a lateral load operates. Considering the results of the analysis according to the unbalanced moment and punching shear on the M-V plane, when only the vertical load operates, the slabs act along the moment line of $\overline{o a b}$, and when it reaches punching failure strength $V_{n P}^{S R}$, it will face shear failure. 


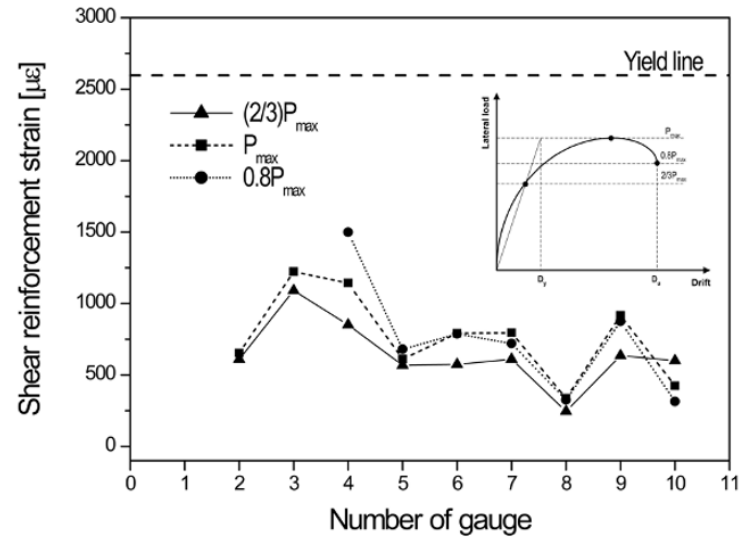

(a) Strain profiles of the SR2(shear stud) shear reinforcement

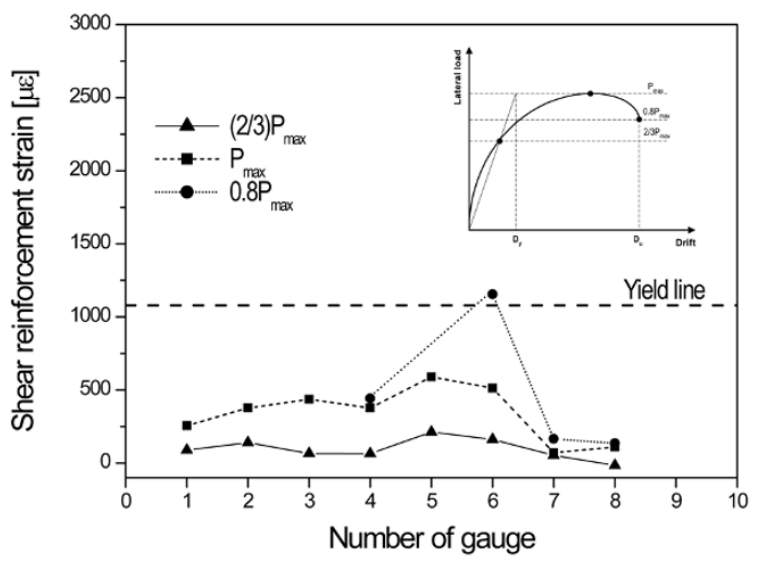

(b) Strain profiles of SR3(shear band) shear reinforcement

Fig. 15 Strain profiles of shear reinforcements.

However, if the lateral load combines with the vertical load, the slabs act along the moment line $\overline{o a c}$, and before reaching $V_{n F}^{S R}$, the lateral load can initially reach $M_{n, u n b}^{S R}$. When the slabs reach the maximum unbalanced moment strength, shear strength can no longer be effective and failure may occur at the effective shear strength $V_{n F}^{S R}$. As a result, slabs that undergo bending governed failure may experience failure at a much lower effective shear strength $V_{n F}$ than either $V_{n P}^{S R}$ or $1.5 V_{n P}$. During this process, the unbalanced moment strength affects the effective shear strength. Figure 15 shows the results of the measuring deformation rate of shear band and shear stud reinforced materials. In all the measurements, the deformation rate of shear reinforcing materials could not reach the yield deformation rate at the lateral displacement ratio when the maximum unbalanced moment appeared. $V_{s}$ in Eq. 1 is based on the assumption that shear reinforcements reach yield strength. However, when bending governed failure occurs because of an unbalanced moment with joints that mainly receive lateral loads, the yield of shear reinforcing materials cannot be secured. The punching shear strength therefore needs to be smaller than $V_{n P}^{S R}$, which is the strength obtained from Eq. 1 (for example, $V_{n F}$ ).

\subsection{Effects on unbalanced moment by the shear reinforcements}

In the design criteria, the punching shear strength increases for joints of slabs with shear reinforcement, such as in Eq. 1. However, in terms of unbalanced moment strength, the punching shear strength is calculated about the slab section with a width of $c_{2}+3 h$,

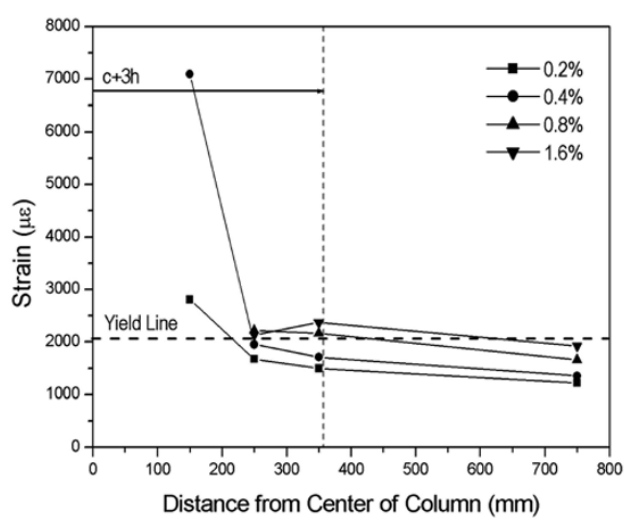

(a) Strain Distribution of top bar with no shear reinforcement(RC1)

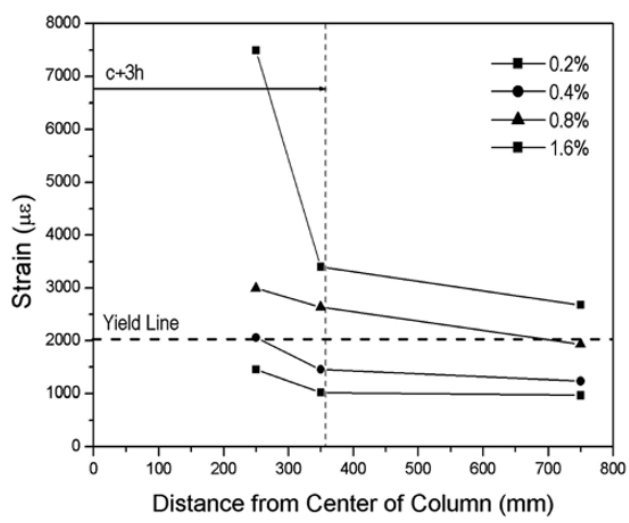

(b) Strain Distribution of top bar with shear band reinforcement (SR3)

Fig. 16 Distribution in steel strain of top bar.

regardless of shear reinforcement. However, if plastic redistribution of flexural reinforcement is smoothly operated with the correct reinforcement of shear reinforced materials, the effective width resistant to the actual unbalanced moment is expanded, leading to an increase in unbalanced moment strength. To consider this phenomenon, bending reinforcement deformation rate and stress status are examined in this study according to the loading stages of specimens and the impact is demonstrated.

Firstly, Figure 16 illustrates the deformation rate of upper reinforcement according to the addition of the level of loading of unreinforced and shear reinforced specimens. In the same displacement ratio between stories, the upper reinforcement deformation rate of the unreinforced specimen (Figure 16(a)) is concentrated on the center of the columns, while the upper reinforcement deformation rate of shear reinforcement specimens (Figure 16(b)) spreads evenly over the slab width. This is because shear reinforcing materials delay punching shear and redistribute the moment acting on the joints in the direction of the slab width.

Figure 17 shows the results of experiments on the stress of upper reinforcement in each specimen and an analysis of the results obtained using $A T E N A^{2}$. From the results, it was found that in the unreinforced specimen, only the reinforcement near the column yields, while in the shear reinforcement specimens, the yielding area of reinforcement is extended to near the boundary of the column strip due to moment redistribution. Shear reinforcements contribute indirectly to flexural reinforcements which can make stress redistribution. 


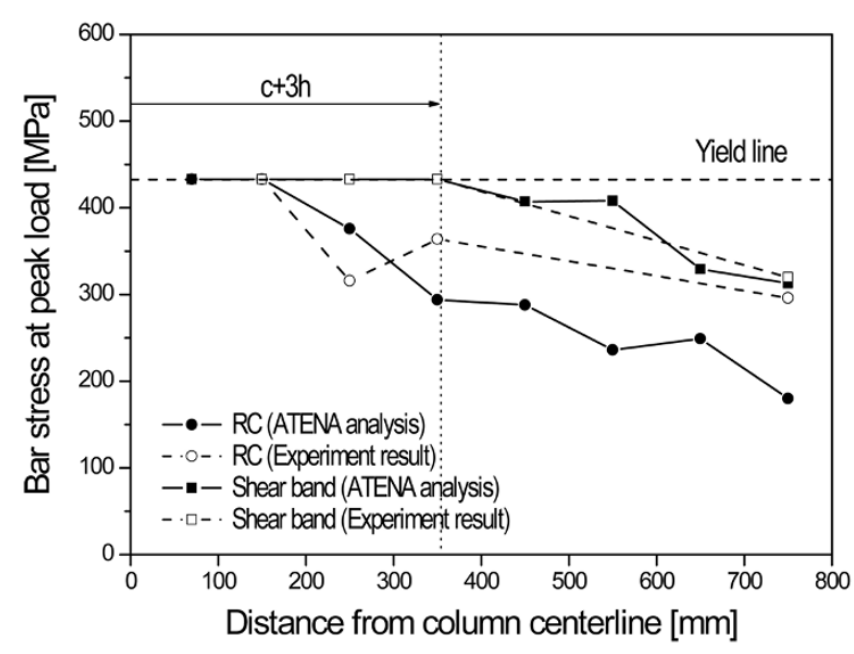

Fig. 17 Distribution in bar stresses at peak load.

To reflect this phenomenon in a structural design, an effective width enlargement factor $\lambda$ is introduced in this study, which applies the effective width of slabs by expanding, depending on the installation of shear reinforcing materials. When we apply an effective width enlargement factor, the effective width of shear reinforcement slabs becomes $\lambda\left(c_{2}+3 h\right)$ by multiplying the effective width of unreinforced slabs that is defined by the structural design criteria by the enlargement factor. Nevertheless, the unbalanced moment strength $M_{n, u n b}^{S R}$ in the shear reinforcement joint is as follows in Eq. 7.

$$
M_{n, \text { unb }}^{S R}=\frac{M_{n, \lambda\left(c_{2}+3 h\right)}}{\gamma_{f}}
$$

In this equation, $M_{n, \lambda\left(c_{2}+3 h\right)}$ is the flexural strength of the slab section, with a width of $\lambda\left(c_{2}+3 h\right)$.

\subsection{Verification of failure mode}

In the experiment for the lateral load of slab-column joints, if the existing study results (Table 1) obtained from a test performed for an unreinforced specimen and the shear reinforced specimens are examined simultaneously, $V_{g} / V_{c}$ (Row 5) is the size of the acting vertical load on punching shear strength of unreinforced slabs (Eq. 5). $M_{\text {test }}^{S R}$ (Row 6) and $V_{\text {test }}^{S R}$ (Row 7) are the results of the experiment carried out on unbalanced moment and punching shear. In addition, Row 9 shows the shear strength ratio in the reinforcement joints against the shear strength of unreinforced joints. If these values and normalized values of the unbalanced moment in Row 6 are compared with the results of the unreinforced specimen in the lateral shear stress model, an equation can be obtained as follows:

$$
\left(\frac{V_{\text {test }}^{S R}}{V_{\text {test }}}\right)=\left(\frac{V_{g}}{V_{\text {test }}}\right)+\left[\left(\frac{\gamma_{v} A_{c} c}{J_{c}}\right)\left(\frac{M_{\text {test }}}{V_{\text {test }}}\right)\right]\left(\frac{M_{\text {test }}^{S R}}{M_{\text {test }}}\right)
$$

However, Eq. 8 does not consider the changes of critical sections according to shear reinforcement.

Figures 18 and 19 illustrate the results of experiments carried out in this study that is defined by using Eq. 8 and the findings from Table 1. In Figure 18, it can be seen that the specimens did not reach the maximum punching shear force, but experienced flexural failure. From this result, we can determine the maximum

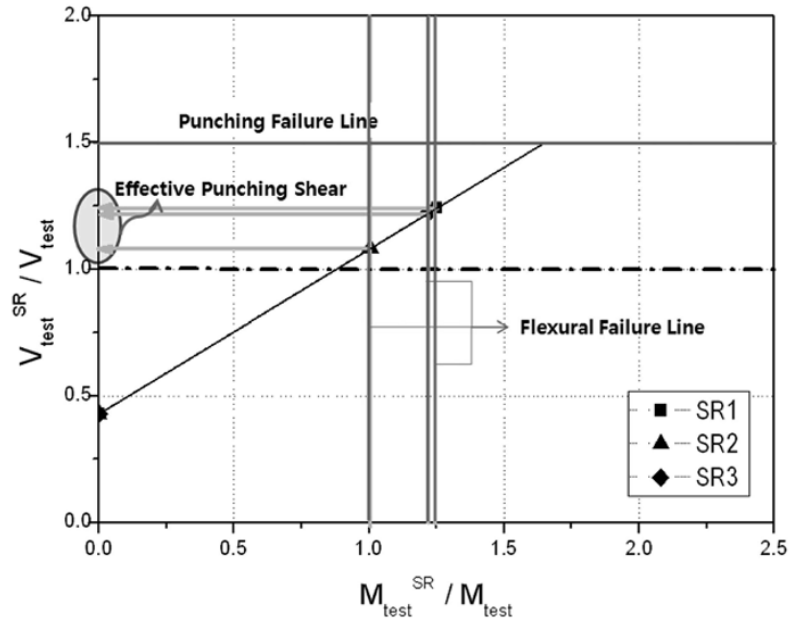

Fig. 18 Graphic representation between unbalanced moment and punching shear for normalized test results.

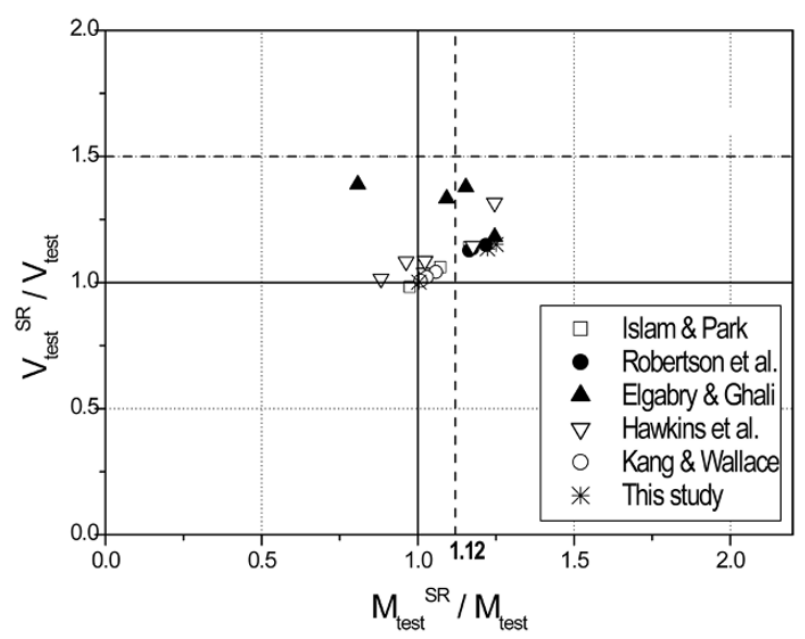

Fig. 19 Enlargement of unbalanced moment of the flat plate connections with shear reinforcements.

capacity of the effective punching shear considering the flexural failure mode from the unbalanced moment. Figure 19 shows the relative increase in the maximum unbalanced moment according to shear reinforcement against unreinforced joints. The behavior of shear reinforced materials differs on the nominal unbalanced moment capacity, yet it increases $12 \%$ on average. If this result is explained by the plastic redistribution of flexural reinforcement by shear reinforcement, the effective width enlargement factor $\lambda$ to define the unbalanced moment strength in Eq. 7 is 1.12 .

\section{Conclusions}

In this study, the unbalanced moment-punching shear is defined on $\mathrm{M}-\mathrm{V}$ plane applying the eccentricity shear stress model presented in ACI 318-08, and the capacity of slab-column connections are studied employing tests about four isolated interior flat slab-column connections under reversed cyclic lateral loading. The following conclusions may be drawn from the present study:

1. These experiments show that the flexural failure mode appears in most specimens with the exception of an unreinforced standard specimen. Installing the correct shear reinforcement may 
improve the seismic capacity of flat plate connections.

2. These experiments showed that the unbalanced moment strength as well as punching shear strength increase by the shear reinforcement for joint of slab. This is caused by the expanded range resistant to the unbalanced moment, which is due to the plastic redistribution of flexural stress by the shear reinforcement. To reflect the effect, it is proposed that the effective width enlargement factor $(\lambda)$ is 1.12 .

3 . The unbalanced moment and punching shear relation proposed in this paper will be useful for defining capacity of effective punching shear strength and designing flat plate slab-column connection.

\section{Acknowledgements}

This study was financially supported by Chonnam National University, 2008.

\section{References}

1. ACI Committee 318, Building Code Requirements for Structural Concrete(ACI 318-08) and Commentary(ACI-318R-08), American Concrete Institute, Farmington Hills, MI, 2008.

2. Atena, ATENA Program Documentation, Cervenka Consulting, Czech Republic, 2000.

3. Elgabry, A. A. and Ghali, A., "Tests on Concrete Slab-Col- umn Connections with Stud-Shear Rein- cement Subjected to Shear-Moment Transfer," ACI Structural Journal, Vol. 84, No. 5, 1987, pp. 433 442.

4. Hawkins, N. M., Bao, A., and Yamazaki, J., "Moment Transfer form Concrete Slabs to Column," ACI Structural Journal, Vol. 86, No. 6, 1989, pp. 705 716.

5. Islam, S. and Park, R., "Tests on Slab-Column Connections with Shear and Unbalanced Flexure," Journal of the Structure Division, Vol. 102, No.3, 1976, pp. 549 568.

6. Joint ACI-ASCE Committee 421, Shear Reinforcement for Slabs, American Concrete Institute, Farmington Hills, MI, 1999.

7. Kang, T. H.-K. and Wallace, J. W., "Seismic Performance of Reinforced Concrete Slab-Column Connections with Thin Plate Stirrups," ACI Structural Journal, Vol. 105, No.5, 2008, pp. $617 \sim 625$.

8. Pilakoutas, K. and Li, X. "Alternative Shear Reinforcement for Reinforced Concrete Flat Slabs.” Journal of Structural Engineering, Vol. 129, No.9, 2003, pp. 1164 1172.

9. Robertson, I. N., Kawai, T., Lee, J., and Enomoto, B., "Cyclic Testing of Slab-Column Connections with Shear Reinforcement," ACI Structural Journal, Vol. 99, No.5, 2002, pp. $605 \sim 613$.

10. The CEB/fib Task Group, Punching of Structural Concrete Slabs, International Federation for Structural Concrete(fib), Lausanne, Switzerland, 2001. 